\title{
Elderly holistic health management model According to the principle of threefold in Thai society
}

\author{
Phrasamu Kantaphat Subhaddo (Charoen Jarasawat) ${ }^{1}$, Boonchurd Chumnisart ${ }^{2}$, Thongdee \\ Sritragarn ${ }^{3}$, Peravat Chaisuk ${ }^{4}$ \\ 1,2,3,4 Faculty of Education, Mahachulalongkornrajavidyalaya University \\ ${ }^{1}$ sin.ngm@mcu.ac.th, ${ }^{2}$ chaibie2529@ @otmail.com, ${ }^{3}$ sombat.cha@mcu.ac.th, ${ }^{4}$ therapong.som@mcu.ac.th
}

\begin{abstract}
The purposes of this research article were 1) to study the state of holistic well-being management, 2) to develop a holistic well-being management model, and 3) to propose a model of holistic well-being management of the elderly according to the threefold training in Thai society. Mixed methods research was designed. Quantitative data were collected from 500 monks and the elderly, and were analyzed by descriptive statistics consisted of percentage, mean, standard deviation including Pearson correlation analysis and model analysis with computer package programs. Qualitative data were collected by interview $10 \mathrm{key}$ informants and focus group discussion with 10 experts. Results indicated that the state of holistic well-being management of the elderly in all 4 aspects was at a high level. All the variables were shown the correlation with statistically significant at the .001 level, and the correlation coefficients ranged from .664 to .839. The correlation matrix between factors was significantly different from the identity matrix. Holistic health management model was developed which consisted of 4 parts: Part 1 Introduction, Part 2 Model, Part 3 Procedure for utilization, Part 4 Conditions for success. A model for the holistic well-being management of the elderly according to the threefold training in Thai society consisted of 4 parts. Part 1: Introduction, Part 2: Prototype of holistic well-being factors on the aspect of physical, mental, social, intellectual/spiritual aspects, and the threefold training including 4 sets of knowledge of selfcare and potential development of the elderly, Part 3 steps of utilization integrated with the threefold training, and Part 4: Conditions for success was validated the model with empirical data (MHHM). The results of 161 tests of the conformity of the model with found that the model was consistent with the empirical data based on the chi-square value $(\cdot 2)=261.89, \mathrm{df}=132, \mathrm{p}=0.089$.
\end{abstract}

Keywords

Model of Holistic Health Management, Elderly According, Threefold Principles

Article Received: 10 August 2020, Revised: 25 October 2020, Accepted: 18 November 2020

\section{Introduction}

Elderly trends during the last 25 years of the 20th century, the elderly population in Thailand grew by 3.7 percent annually, the highest rate in East and Southeast Asia [1]. In 2000, Thailand had 9.6 percent of the elderly population, which is the largest in Southeast Asia. This proportion rose to 11.5 percent in 2010, compared with the United Nations designation. Considered that Thailand has entered the aging society initially. It is estimated that the proportion of the elderly will increase to 19.1 percent in 2025 and 26.4 percent in 2050. This increase in the aging population is faster than it was in many western countries times [2].

The Ministry of Social Development, Human Security, states that advancing to an aging society is a problem in which the government has to formulate strategies for planning to support it because while the number of older people increases. The number of children and laborers will be reduced. The proportion of the labor force (aged 15-59) in the total population will drop from 67.6 percent in 2010 to 65.9 percent and 61.4 percent in 2020 and 2030 , respectively. The proportion of elderly people (age 60 years and over) will increase from 11.9 percent to 17.5 percent and 25.1 percent over the same period. As a result, workers will have to bear the burden of taking care of the elderly more .6 In 2007, 6 workers have burden to care for the elderly, but it is expected that in the year 2027, 3 workers will have to take care of the elderly .1 elderly. In addition, demographic change is a pressure to make the Thai elderly a major risk group. In addition to the health risks that create limitations in our daily life, Thai elderly also have economic risk, because there is no income guarantee and have insufficient income to live and has a high proportion that fall under the poverty lime in the future, caring for the elderly by grandchildren is part of Thai culture [3].

While the population structure of Thailand has changed dramatically, evolution of medical and public health technology causing the Thai people to live longer, the number of elderly population increasing childhood and labor population declining during the 11th National Economic and Social Development Plan (2012-2016) from the proportion of child population: labor: elderly $20.5 \%$ : $67.6: 11.9 \%$ in 2010 to $18.3 \%$ : $66.9: 14.8 \%$ in the year. The index results in planning to develop the country to accommodate the growing elderly in the future [4].

The top executives of all 4 ministries consist of the Ministry of Interior Ministry of Social Development and Human Security Ministry of Education and Ministry of Public Health Led by the Minister of Public Health realized the importance and urgent need for operational integration. Since the policy level framing of strategic goals, measures and making action plans for driving into action at the local level for clarity based on vision and goals and strategy according to the 2nd National Plan on the Elderly (20022021), revised No. 1, 2009, as follows: vision: "The elderly are the milestones of society." The goal of the elderly can take care of themselves able to support daily life and have a good quality of life set 3 common strategic goals (3S), including 1) Social Participation. (Promoting participation in society), 2) Social Security (promoting security), 3) Strong 
Health (promoting good health) and setting indicators for 5 years (2013-2017) to it is a guideline to drive effective implementation at the local level and achieve the next goal [5].

Phra Promkhunaporn (P.A.Payutto) [6] explains that "wellbeing" or "health" is the same word in Pali, but the Thai language praises "W" as " $\mathrm{Ph}$ " as "health" when the meaning of health is physical, mental, social and intellectual health, so it means near happiness. The state of being unhappy is a perfect state. The modern term is called "Holistic", Buddhist happiness or Buddhist health consisting of transcendence (Brightness) Wimutti (liberation) Wisutti (purity, not frustrated, gloomy) Peace (not anxious, anxious), which is a condition that is the goodness of life. [7] Mentioning the well-being of the holistic life that can be enjoyed must manage the mind to have a positive mental state True health must follow the truth of the nature of life. What is the body of a healthy life? How do body and mind relate to the environment? To be successful, you must develop your mind and intelligence. Intelligence is a key element in the way we relate to the environment and the state of mind with wisdom to illuminate the pathway to guide the principles of human development of Buddhism, holistic development is therefore directly about well-being which is consistent with the threefold principle in terms of human development in the book of Buddhism that "If speaking in the language of modern scholars or according to the principles of education in the Eastern line, Athisilasikkha, Athichittasikkha and Athipanyasikka covers the realization of social development, emotional development, and intellectual development, respectively. It is, but will differ in scope of meaning and Sikkha 3 has a specific purpose in line with Buddhism. A person must be trained to discipline (including responsibility and good social relationships) to grow emotionally. (The monk said that the mind is strong, refined, has good quality and competence) and the cognitive growth (beginning with a rationale) Sikkha 3 together and complement each other threefold is a training system from outside to find inside from the rough, go to the fine parts. And from the simpler parts to the harder and deeper parts. When practicing in the inner detail, the mental and intellectual stages. As a result, it returns to help living outside, such as having a stable and honest behavior, selfdiscipline, not having to reluctance or concentrate on controlling, maintaining, thinking, solving problems and doing various activities with pure wisdom by implication, when practicing throughout the system of science and then the whole life system became the system of Makkah, they're all consistent inside and out. "[8]

The development of training for the elderly is another way to prepare for the structural changes of the population to enter the aging society. It is an issue that is gaining great attention, both nationally and globally, due to its widespread impact at the macro level: impact on gross domestic product (GDP), per capita income, savings, investments, government budget, employment, labor productivity, and micro levels, including their impact on various markets, products and services, especially in the financial and health aspects; it is urgent that systematic planning is needed and take action in advance as measures in many respects, they take time to implement. Before seeing tangible results [9].
From the background and importance of the problem Therefore, the researcher is interested in studying the holistic health management model of the elderly according to the three-Sikkha principle in Thai society as a guideline for promoting. Developing the overall well-being of the elderly through the three-fold principle for better quality Able to carry on with their daily life.

\section{Research Objectives}

The purposes of this research article were 1) to study the state of holistic well-being management, 2) to develop a holistic well-being management model, and 3) to propose a model of holistic well-being management of the elderly according to the threefold training in Thai society.

\section{Research Methods}

Step 1: To study the overall well-being of the elderly in Thai society, there are 3 steps: 1) Study documents on the study of the overall health management of the elderly in Thai society. Research textbook website Results: Information on the overall health management status of the elderly in Thai society 2) Study of the holistic health management of the elderly according to the Tri-sikkha principles in Thai society distribute questionnaires on the overall health management status of the elderly in Thai society from monks and elders in temples of Thailand using a 1: 20 parameter based on the concept of Hair, 500 samples were obtained. Distribution coefficient (C.V.), skewness and kurtosis with a program, interviewed 10 Key informants on the overall health management of the monks and the elderly in Thai society. The second step is to develop a model of the holistic wellbeing of the elderly according to the Tri-Sikkha principles in Thai society, there are 2 steps: Developed by discussing resource groups: qualified persons / scholars / seniors by purposive sampling, specifying criteria for the selection of 10 key informants.

The third step is to propose a model of holistic health management for the elderly according to the Tri-Sikkha principles in Thai society from objective item 2 , the results of the examination of the holistic health management model for the elderly according to the Tri-Sikkha principles in Thai society. The holistic health management model was analyzed the elderly according to the Tri-Sikkha principles in Thai society to examine the consistency of the holistic health management model of the elderly according to the three-sided principle of the Thai society with empirical data. Analysis of confirmation elements (Confirmatory Factor Analysis: CFA) to examine the consistency of the holistic health management model of the elderly according to the Tri-Sikhism principles in Thai society with empirical data by using computer program. Results were obtained from data analysis to examine the consistency of the elderly holistic health management model according to the TriSikkha principles in Thai society. Improve and present the model of holistic well-being management of the elderly according to the Tri-Sikkha principles in Thai society. 


\section{Research Results}

1. Results of the study of the overall health management status of the elderly in Thai society. The research results were found that the monks over the age of 60 and the elderly had opinions on the overall health management of the elderly in Thai society in all four areas. Considering each side found that all aspects were at a high level in descending order is physical well-being (3.88), social well-being (3.78), cognitive / spiritual well-being (3.66) and mental well-being (3.62), respectively, as shown in Table 1.

Table 1 Shows the mean and standard deviation of the respondents based on their opinions on the 4 aspects of the overall health management of the elderly in Thai society

\begin{tabular}{|c|c|c|c|c|}
\hline & Studied variables & $\overline{\bar{x}}$ & S.D. & Rating \\
\hline 1. & Physical health & 3.88 & 0.764 & high \\
\hline 2. & $\begin{array}{l}\text { Psychological } \\
\text { wellbeing }\end{array}$ & 3.62 & 0.857 & high \\
\hline 3. & Social well-being & 3.78 & 0.917 & high \\
\hline 4. & $\begin{array}{c}\text { Cognitive / spiritual } \\
\text { well-being }\end{array}$ & 3.66 & 0.885 & high \\
\hline & Total & 3.74 & 0.781 & High \\
\hline
\end{tabular}

The results of the preliminary statistical analysis of the state of the holistic health management of the elderly in all four aspects of Thai society were found to be at the high level of all considering the skewness of the overall health management status of the elderly in Thai society. Most of them had a negative skewness value show that the monks aged 60 years and over and most of the elderly had opinion that was above average and the distribution of the data is similar to the normal curve and considering the value, it was found that the overall health management condition of most of the elderly in Thai society was negative, indicating that the distribution characteristics of the data were less than the normal curve. The information is not distributed much and when considering the distribution coefficient (C.V.), it was found that the data were similar. There is little distribution of information as in Table 2 as follows.

Table 2 The overall health management status of the elderly in Thai society using descriptive statistics.

\begin{tabular}{|c|c|c|c|c|c|}
\hline $\begin{array}{l}\text { The overall } \\
\text { health } \\
\text { management of } \\
\text { the elderly in } \\
\text { Thai society }\end{array}$ & Mean & S.D. & Sk & Ku & C.V. \\
\hline Physical health & 3.88 & 0.764 & $\begin{array}{c}- \\
.700\end{array}$ & 0.311 & 0.24 \\
\hline $\begin{array}{l}\text { Psychological } \\
\text { health }\end{array}$ & 3.62 & 0.857 & $\begin{array}{c}- \\
.397 \\
\end{array}$ & 0.298 & 0.20 \\
\hline Social health & 3.78 & 0.917 & $\begin{array}{c}- \\
.517 \\
\end{array}$ & $\begin{array}{c}- \\
0.344 \\
\end{array}$ & 0.10 \\
\hline $\begin{array}{c}\text { Cognitive health } \\
\text { Soul }\end{array}$ & 3.66 & 0.885 & $\begin{array}{c}- \\
.470 \\
\end{array}$ & $\begin{array}{c}- \\
0.232 \\
\end{array}$ & 0.17 \\
\hline
\end{tabular}

The correlation analysis results of the overall health management status of the elderly in Thai society were all statistically significant at the level of .001 . The relationships between the elements were significantly different from the identity matrix and the overall health management status of the elderly in Thai society is sufficiently related able to analyze the model of the holistic health management of the elderly according to the three-sided principles in Thai society as shown in Table 3:

Table 3 Mean, Standard Deviation and Pearson Correlation Coefficient The overall health management of the elderly in Thai society.

\begin{tabular}{|c|c|c|c|c|}
\hline $\begin{array}{c}\text { Variable } \\
\text { s }\end{array}$ & $\begin{array}{c}\text { Bod } \\
y\end{array}$ & $\begin{array}{c}\text { Min } \\
\text { d }\end{array}$ & $\begin{array}{c}\text { Socia } \\
\text { I }\end{array}$ & $\begin{array}{c}\text { Wisdo } \\
\text { m }\end{array}$ \\
\hline 1. Body & 1.000 & & & \\
\hline 2. Mind & $.704^{* 8}$ & 1.000 & & \\
\hline 3. Social & $.667^{12}$ & $.829^{\prime \prime}$ & 1.000 & \\
\hline 4. Wisdom & $.664^{\prime \prime}$ & $.839^{\prime \prime}$ & $.836^{\prime \prime}$ & 1.000 \\
\hline Mean & 3.88 & 3.62 & 3.78 & 3.66 \\
\hline S.D. & 0.764 & 0.857 & 0.917 & 0.885 \\
\hline \multicolumn{5}{|c|}{ Kaiser-Meyer-Olkin Measure of Sampling Adequacy $=.849$} \\
\hline $\begin{array}{l}\text { Bartlett's Test of } \\
\text { value }(\mathrm{sig})=0\end{array}$ & & & quare $=1$ & $13 \mathrm{df}=6 \mathrm{p}$ \\
\hline
\end{tabular}

The results of interviews with the monks and the elderly in Thai society, 10 key informants, with specific qualifications were those who played a role in promoting the holistic wellbeing of the elderly or people over 60 years of age with complete physical health. There are four aspects of the overall health management of the elderly in Thai society: 1) physical well-being, 2) psychological well-being, 3) social well-being, 4) cognitive / spiritual health. The elderly should follow 5 states: food, vegetables, fish, food, should eat about $80 \%$ will improve our health, weather, mood, exercise and danger, not consuming things that are not beneficial to the body able to adapt to society and environment accept the truth about yourself. Understanding the differences between individuals take responsibility stay with family spend time with children, avoiding sympathizers. There is a rule by visiting relatives once a week, knowing and understanding separately. In the reason of good, evil is a good example for children, has a public mind, respectfulness, honoring the 5 precepts will be good for health by letting the elderly pray Samatha- concentrates on the activities of the community every week.

2. Develop a holistic health management model for the elderly according to the three-sided principles in Thai society consisting of 4 parts as follows:

Part 1: namely 1) Environment, both internal and external environment must be favorable including the difference between the characteristics of the elderly. 2) Principle including the basic concept and conditions of use. Conditions for successful implementation of the pattern and precautions to prevent problems that may arise, including viewing and the elderly in 4 ways: family care, institutional care, community care, caring in special situations. 3) Objectives: 8 objectives for caring for the elderly.

Part 2: The model consists of 1) System, including 1) elements of holistic well-being. There are 5 key components: 1) physical well-being, 2) psychological wellbeing, 3) social well-being, 4) cognitive/spiritual well-being and health conditions according to the Tri-Sikkha principles; and development of "good health" abilities for the elderly; 
2) psychological well-being and develop the potential of the elderly "Security in life", 3) social well-being, knowledge book, self-care and develop the potential of the elderly "Social learning", 4) health, intellectual/spiritual, self care knowledge book and develop the potential of the elderly "have a job" 3) Management Process: Elderly care according to the rights of the elderly according to the United Nations on the care of the rights of the elderly. If it optimized for Thailand, the researcher opines that the government should set guidelines for the development of the elderly in various forms with the basic concept of today's elderly.

Part 3 steps to apply it consists of 1) Structure is the mutual link between various elements. This will help make the elderly holistic health management model in accordance with the Tri-sikkha principles of Thai society to be effective. 2) Decision - making process or well assessed that as a way to achieve the objectives and the goal of the pattern which has the criteria for making decisions, which are fundamental factors that enable people in society to take care of managing the overall well-being of the elderly successfully implemented the holistic health management model of the elderly according to Tri-Sikkha principles of the Thai society for the benefit of checking how much the format functions as designed. These three principles are simply called precept (Sila), meditation (Samadhi), and total wisdom (Panna) called "Tri-Sikkha" depending on the context of Thai society, such as the physical condition of the elderly, psychological condition of the elderly, social conditions of the elderly, economic conditions of the elderly, and government policies.

Part 4 conditions for success depends on the context of Thai society, such as the physical condition of the elderly, psychological condition of the elderly, social conditions of the elderly, economic conditions of the elderly, and government policies.

3. Propose a model of holistic well-being management of the elderly according to the threefold training in Thai society.

A complete model of the holistic well-being of the elderly in Thai society consists of 4 parts:

Part 1: The leading part is 1) environment, both internal and external environment must be favorable including the difference between the characteristics of the elderly. 2) Principle including the basic concept and conditions of use. Conditions for successful implementation of the pattern and precautions to prevent problems that may arise including viewing and the elderly in 4 ways: family care, institutional care, community care, caring in special situations. 3) Objectives: 8 objectives for caring for the elderly.

Part 2: The model consists of 1) system including 1) elements of holistic well-being. There are 5 key components: 1) physical well-being, 2) psychological wellbeing, 3) social well-being, 4) cognitive/spiritual well-being and health conditions according to the Tri-Sikkha principles; development of "good health" abilities for the elderly; 2) psychological well-being and develop the potential of the elderly "security in life", 3) social well-being, knowledge book, self-care and develop the potential of the elderly "Social learning", 4) health, intellectual/spiritual, self care knowledge book and develop the potential of the elderly "have a job" 3) Management Process: elderly care according to the rights of the elderly according to the United Nations on the care of the rights of the elderly. If it is optimized for Thailand, the researcher opines that the government should set guidelines for the development of the elderly in various forms with the basic concept of today's elderly.

Part 3 steps to apply it consists of 1) structure is the mutual link between various elements. This will help make the elderly holistic health management model in accordance with the Tri-sikkha principles of Thai society to be effective. 2) Decision Making process or well assessed that as a way to achieve the objectives and the goal of the pattern which has the criteria for making decisions, which are fundamental factors that enable people in society to take care of managing the overall well-being of the elderly successfully implemented the holistic health management model of the elderly according to the Tri-sikkha as in Fig.1.

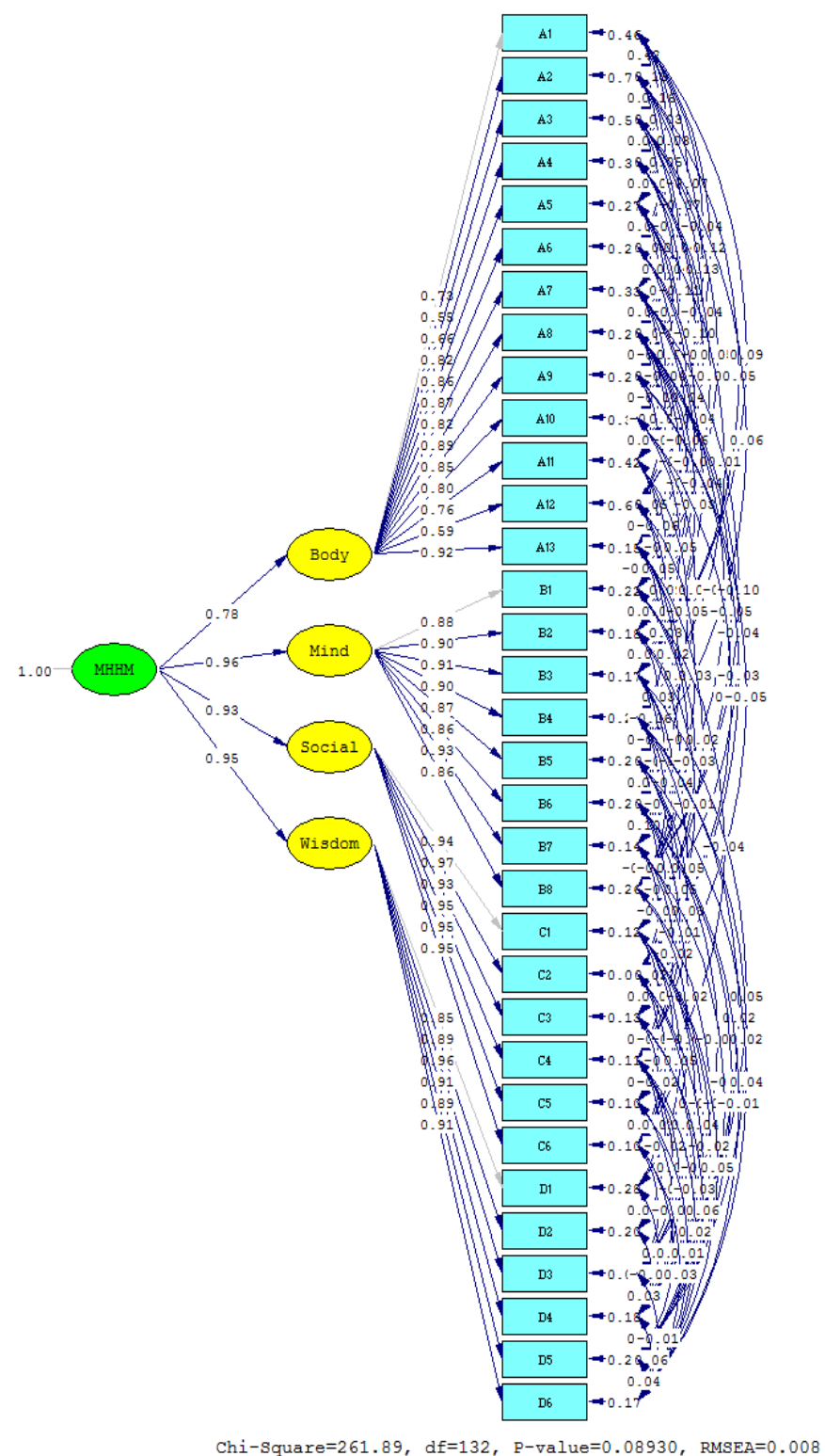

Fig. 1 The results of the verification of the conformity of the holistic health management model of the elderly according to the threefold principle in Thai society, created with empirical data 


\section{Discussions}

The researcher found the following important points to discuss the results of the elderly holistic health management model in the Thai society as follows:

1. The results of the study of the overall health management status of the elderly in Thai society found that the monks aged 60 years and older and the elderly had opinions on the overall health management of the elderly in Thai society. Overall, there were opinions at a high level in all aspects and variables considering the skewness of the overall health management status of the elderly in Thai society. Most of them had a negative skewness value showed that the monks aged 60 years and over and most of the elderly had opinion that was above average, the distribution of the data is similar to the normal curve, considering the value, it was found that the overall health management condition of most of the elderly in Thai society was negative, indicating that the distribution characteristics of the data were less than the normal curve. The information is not distributed much, considering the distribution coefficient (C.V.), it was found that the data were similar that had little distribution of information. All of them were statistically significant at the 0.001 level. The correlation coefficient range was between .664 and .839. The correlation matrix characteristics between the elements were statistically significant different from the identity matrix and the overall health management status of the elderly in Thai society is sufficiently related able to analyze the model of the holistic health management of the elderly according to the Tri-Sikkha principles in Thai society, which is consistent with the results of interviews with the monks and the elderly in Thai society. The elderly should follow 5 states: food, vegetables, fish, food, should eat about $80 \%$ will improve our health, weather, mood, exercise and danger, not consuming things that are not beneficial to the body Able to adapt to society and environment accept the truth about yourself. Understanding the differences between individuals take responsibility stay with family spend time with children, avoiding sympathizers. There is a rule by visiting relatives once a week, knowing and understanding separately. In the reason of good, evil is a good example for children, has a public mind, respectfulness, honoring the 5 precepts will be good for health by letting the elderly pray Samatha-concentrates on the activities of the community every week. The results of this research are consistent with the research of Phramaha Pongprida Paripunno (Champasri) proposed a thesis on "Prevention and treatment of diseases according to Buddhism". This thesis aims to study the nature and causes of physical and mental illnesses and to study the treatment of such diseases that appeared in the Tipitaka and commentary on the study found that Buddhism categorizes disease into two categories: first, physical disease is caused by four elemental imbalances, variations in the seasons, irregular physical exercise in the past and present life, etc. This physical disease has 3 methods of treatment: (1) medical treatment such as using herbal medicine, (2) Dhamma therapy is practice meditation, (3) psychic healing such as the use of Putthanupab (power of Buddha) Secondly, psychological diseases are caused by obsessive passion. There are 3 levels of destructive passion, such as Nukasai, medium desires such as neutrals, and crude passions, such as hurting others, stealing, mental illness. That can be treated with Vipassana . In addition, according to the principles of Buddhism Prevention of disease must be followed by three principles, including precepts, meditation and wisdom [10].

2. Develop a holistic health management model for the elderly according to the Tri-Sikkha principles in Thai society, consisting of 4 parts as follows:

Part 1, namely 1) Environment both internal and external environment must be favorable including the difference between the characteristics of the elderly. 2) Principle including the basic concept and conditions of use. Conditions for successful implementation of the pattern and precautions to prevent problems that may arise including viewing and the elderly in 4 ways: family care, institutional care, community care, caring in special situations. 3) Objectives: 8 objectives for caring for the elderly.

Part 2: The model consists of 1) System, including 1) Elements of holistic well-being. There are 5 key components: 1) physical well-being, 2) psychological wellbeing, 3) social well-being, 4) cognitive/spiritual well-being and health conditions according to the Tri-Sikkha principles; development of "good health" abilities for the elderly; 2) psychological well-being and develop the potential of the elderly "Security in life", 3) social well-being, knowledge book, self-care and developing the potential of the elderly "Social learning", 4) health, intellectual/spiritual, self care knowledge book and develop the potential of the elderly "have a job", 3) Management Process: elderly care according to the rights of the elderly according to the United Nations on the care of the rights of the elderly. If it optimized for Thailand, the researcher opines that the government should set guidelines for the development of the elderly in various forms with the basic concept of today's elderly.

Part 3 steps to apply it consists of 1) Structure is the mutual link between various elements. This will help make the elderly holistic health management model in accordance with the Tri-sikkha principles of Thai society to be effective.

2) Decision-making process or well assessed that as a way to achieve the objectives and the goal of the pattern has the criteria for making decisions, which are fundamental factors that enable people in society to take care of managing the overall well-being of the elderly Successfully implemented the holistic health management model of the elderly according to the three-sided principle of the Thai society for the benefit of checking how much the format functions as designed. These three principles are simply called precept (Sila), meditation (Samadhi), and total wisdom (Panna) called "Tri-Sikkha" depending on the context of Thai society, such as the physical condition of the elderly, psychological condition of the elderly, social conditions of the elderly, economic conditions of the elderly, and government policies.

Part 4 conditions for success depend on the context of Thai society, such as the physical condition of the elderly. psychological condition of the elderly, social conditions of the elderly, economic conditions of the elderly, and government policies. The results of this research reflect that the three-part elderly holistic well-being model in Thai society relies on the four essential elements of the model, and each of them plays an important role in the 
implementation of the model to promote the holistic wellbeing of the elderly. Elderly are cared for Keep it intact The findings of this research are consistent with Phra Phromkunaporn (P.A.Payutto) wrote a book on "Modern Medicine in Buddhism" is a collection of writings about medicine and health care as well as ethical problems related to modern medicine according to Buddhism principles. The content is divided into 5 parts: Part 1 patient: sick but the body and heart are happy. There are 4 topics, Dhamma Talk for patients' Relatives, Buddhist Methods for Rehabilitation of Health: Substances of Health and Integrity and Buddhism and Organ Donation, Part 2: Medicine: Patients, Hope, Worship Society consists of Keep the heart in mind when treating patients. Globalization: the role of doctors and the hope of patients Internal Medicine and Ethics Problems And medical ethics for the new millennium, part 3 medicine: reliance on all eras contain The Fundamentals of Medical Medicine: Advancing in the Crisis Age Studying Medicine in Thai Society and Buddhist medicine. Region 4 Medical problems: the world grows more and more people face, Help me die quickly or help me die, Karma and Genetic Diseases in Buddhism Abortion, Assorted Questions and Answers: Modern Medical Technology and Ethics in Buddhism and Life, Ethics and Medical Research, Part 5: Civilization Example: Civilization must have an answer, Contain Dharma wins AIDS [11].

3. To propose a model for the holistic health management of the elderly according to the Tri-Sikkha principles in Thai society.

A complete model of the holistic well-being of the elderly in Thai society consists of 4 parts:

Part 1: The leading part is 1) environment both internal and external environment must be favorable including the difference between the characteristics of the elderly. 2) Principle including the basic concept and conditions of use. Conditions for successful implementation of the pattern and precautions to prevent problems that may arise including viewing and the elderly in 4 ways: family care, institutional care, community care, caring in special situations 3) Objectives: 8 objectives for caring for the elderly.

Part 2: The model consists of 1) system, including 1) elements of holistic well-being. There are 5 key components: 1) physical well-being, 2) psychological wellbeing, 3) social well-being, 4) cognitive/spiritual well-being and health conditions according to the Tri-Sikkha principles; development of "good health" abilities for the elderly; 2) psychological well-being and develop the potential of the elderly "Security in life", 3) social well-being, knowledge book, self-care and develop the potential of the elderly "Social learning", 4) health, intellectual/spiritual, self care knowledge book and develop the potential of the elderly "have a job" 3) Management Process: Elderly care according to the rights of the elderly according to the United Nations on the care of the rights of the elderly. If It optimized for Thailand the researcher opines that the government should set guidelines for the development of the elderly in various forms with the basic concept of today's elderly.

Part 3 steps to apply it consists of 1) Structure is the mutual link between various elements. This will help make the elderly holistic health management model in accordance with the three-sided principle of Thai society to be effective.
2) Decision Making process or well assessed that as a way to achieve the objectives and the goal of the pattern has the criteria for making decisions, which are fundamental factors that enable people in society to take care of managing the overall well-being of the elderly successfully implemented the holistic health management model of the elderly according to the three-sided principles of the Thai society for the benefit of checking how much the format functions as designed. These three principles are simply called precept(Sila), meditation (Samadhi), and total wisdom (Panna) called "Tri-Sikkha" depending on the context of Thai society, such as the physical condition of the elderly, psychological condition of the elderly, social conditions of the elderly, economic conditions of the elderly, and government policies.

Part 4 conditions for success depend on the context of Thai society, such as the physical condition of the elderly. Psychological condition of the elderly, social conditions of the elderly, economic conditions of the elderly, and government policies.

The results of the examination of the conformity of the holistic health management model of the elderly according to the Tri-Sikkha principles in Thai society created with empirical data. The model of the holistic well-being of the elderly according to the Tri-Sikkha principles in Thai society with empirical data (MHHM), the researcher has adjusted the model of the holistic well-being of the elderly according to the Tri-Sikkha principles in Thai society 161 times, it was found that the model was consistent with the empirical data based on the chi-square values $(\cdot 2=261.89$, $\mathrm{df}=132, \mathrm{p}=0.089)$, which differed from zero. The harmonization index (GFI) is 0.849 , the corrected degree of harmony index (AGFI) is 0.744 , the square root of the residual mean (RMR) is 0.03 and the root. The second of the mean quadratic error of the estimation (RMSEA) is 0.008 , indicating that the model is consistent with the empirical data. There are four sets of knowledge of self-care and development of the elderly in life security including 1) physical health, self-care knowledge book and developing the potential of "healthy" elderly, 2) psychological wellbeing and develop the potential of the elderly "Security in life", 3) social well-being, knowledge book, self-care and developing the potential of the elderly "Social learning" 4) health, intellectual / spiritual, self-care knowledge book and developing the potential of the elderly. The results of this research show that the monks and the elderly have opinions that are consistent with the empirical data of the elderly holistic well-being model in Thai society. It can be integrated into the promotion of the holistic well-being of the elderly with a threefold principles for the elderly to have complete physical, mental, social and intellectual health. In line with the research of Assoc. Prof. Pittaya Jarupunpol and the Faculty proposes a research project on "Well-being of the monks in Bangkok: situation, problem, solution And promote holistic health "by studying the monks from 3 districts of Bangkok, namely the inner, middle and outer layers, totaling 31 temples, 417 monks participated in the project between October 2003 - July 2004. The purpose of this study was to assess well-being of the monks in a holistic way from situations, problems, solutions and promote holistic health. The study found that most monks range from 20-30 years in health care behaviors such as food 
consumption exercise physical examination is in the fair level. The factors that influenced health care behavior were self-efficacy, age, perception, barriers and perceived health status and the perception of the benefits of self-care, etc. For mental health, it was found that monks have high stress levels and factors affecting the care and stress therapy are stress level social support, age, education level, magazine factors. The environmental health aspects of the temples are low to medium. Most temples do not have a systematic development plan. Environmental sanitation in housing and solid waste management needs to be improved urgently. [12] In line with the research of Sri Muang Phangrit, studied the quality of life development of the elderly by themselves, their families and communities in Ayutthaya Province. It consists of 5 areas: physical, mental, environmental, social relations and satisfaction and found that all 16 independent variables were able to explain the variation in the quality of life of the elderly. The social, environmental, psychological, and satisfaction relationships were $33.8 \%, 17.9,13.2,9.7$ and $9.3 \%$ respectively. The guidelines for developing the quality of life for the elderly required at the individual level consisted of preparation of knowledge and practice in health from adulthood. Children until old age financial preparation by saving money since working age to facilitate being an elderly person who can rely on themselves. At the family level, children should have gratitude, love, warmth providing support to the elderly for the community level elderly should be encouraged to play roles and participate in community activities build a strong community, motivate community, leaders, and people to think together to create activities according to the needs and in harmony with the way of life by relying on local wisdom and resources being a good example focus on being proactive In the development of knowledge and cooperation work to improve the quality of life of the elderly [13].

\section{Conclusion}

The development of the holistic well-being of the elderly according to the three-fold principle is physical well-being having a healthy body without disease, not starving, there are four factors that are sufficient for the convention, psychological well-being. To think for a systematic reason having a heart that is fresh, cheerful, radiant, peaceful, known to let go in various problems complete with mental health, having a strong mind, stability, social well-being, having relationships with family members, having a supportive relationship with the environment, having a good life, having the right to freedom that is protected able to adapt to change cognitive / spiritual well-being, training for intellectual development, enhancing knowledge, and thinking, having the knowledge and good idea, the job and the right, having good mental health. There is a sacrifice benevolence. There is religion as an anchor of the mind, integrated with three principles: 1) The precepts are the development of social relations, having a supportive relationship with the social environment, having good behavior in relation to fellow human beings with discipline. The elderly can adjust to live well with their family and society with precepts as a factor for good health, 2) Meditation is to develop the mind to be more prosperous, good, strong, happy, the elderly who have faith in Buddhism will develop compassion and follow meditation. This will help to have a more peaceful mind ready to develop intelligence, 3) Intelligence is the development of intelligence, training to develop wisdom to create knowledge, thinking, and understanding to think, consider and solve problems with intelligence. having a happy heart, without suffering, wisdom is the real solution to problems by virtue of a solution to life problems to live with the family, a peaceful and sustainable society.

\section{References}

[1] UNFPA, ICPD at Progress and Challenges in Implementing the Programme of Action in Thailand. Nonthaburi: Ministry of Public Health, 2010.

[2] United Nations Population Division, World Population Prospects: The 2008 Revision New York: UN, 2009.

[3] Ministry of Social Development and Human Security, Strategy for Human Security 2013-2023, Bangkok.

[4] Office of the National Economic and Social Development Board, 2010 Annual Meeting Document, Direction of the $11^{\text {th }}$ Development Plan.

[5] Office of the Permanent Secretary, Ministry of Public Health, Bureau of Policy and Strategy, Manual of Integration of Cooperation 4, Ministry of Human Development throughout the life of the elderly, documents for the signing ceremony of the Memorandum of Understanding on the Integration of Cooperation on People Development throughout their life, 30 March 2017.

[6] Phra Brahma Kunaporn (P.A. Payutto), A Buddhist holistic well-being. 5th edition, Bangkok, 2006.

[7] Phra Dharmitaka (P.A. Payutto). (2000a). Phutthatham, revised and expanded version, $9^{\text {th }}$ Edition, Bangkok: Mahachulalongkornrajavidyalaya University.

[8] C. Phromphak, Access to Aging Society of Thailand, Aging society in Thailand, Secretariat of the Senate Year 3 Issue 16 August 2013.

[9] Phramaha Pongprida Paripunno (Champasri), "Prevention and Treatment 
of Diseases according to Buddhism", Master's Thesis, Graduate School: Mahachulalongkornrajavidyalaya University, 2002.

[10] Phra Promkhunaporn (P.A.Payutto), New Era Medicine in Buddhism, 5th edition (Additional update) Memorial cremation ceremony Professor Dr. Yusawad, NCC., MD, (Bangkok: Sahathamik Company Limited, 2007).

[11] P. Jarupoonphol and team, The well-being of the monks in Bangkok: situation, problem, solution and promote holistic health, research project of the Faculty of Public Health Department of Family Health: Mahidol University, 2004.

[12] S. Plangrit, "improving the quality of life for the elderly by oneself Family and community Phranakhon Si Ayutthaya Province ", Ph.D. Thesis (Sacha of Demography), College of Population Studies: Chulalongkorn University, 2004. 